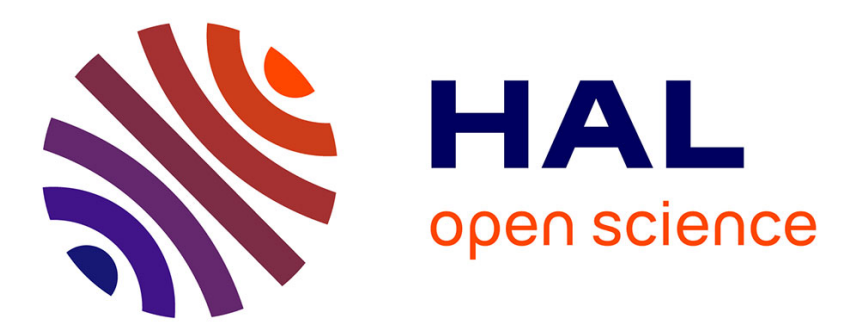

\title{
Influence of fibre distribution and grain size on the mechanical behaviour of friction stir processed $\mathrm{Mg}-\mathrm{C}$ composites
}

\author{
Anne Mertens, Aude Simar, Jérôme Adrien, Eric Maire, H-M Montrieux,
} Francis Delannay, Jacqueline Lecomte-Beckers

\section{To cite this version:}

Anne Mertens, Aude Simar, Jérôme Adrien, Eric Maire, H-M Montrieux, et al.. Influence of fibre distribution and grain size on the mechanical behaviour of friction stir processed $\mathrm{Mg}-\mathrm{C}$ composites. Materials Characterization, 2015, 107, pp.125-133. hal-01538203

\section{HAL Id: hal-01538203 https://hal.science/hal-01538203}

Submitted on 9 Feb 2022

HAL is a multi-disciplinary open access archive for the deposit and dissemination of scientific research documents, whether they are published or not. The documents may come from teaching and research institutions in France or abroad, or from public or private research centers.
L'archive ouverte pluridisciplinaire HAL, est destinée au dépôt et à la diffusion de documents scientifiques de niveau recherche, publiés ou non, émanant des établissements d'enseignement et de recherche français ou étrangers, des laboratoires publics ou privés. 


\title{
Influence of fibre distribution and grain size on the mechanical behaviour of friction stir processed $\mathrm{Mg}-\mathrm{C}$ composites
}

\author{
A. Mertens ${ }^{\mathrm{a}, *}$, A. Simar $^{\mathrm{b}}$, J. Adrien ${ }^{\mathrm{c}}$, E. Maire ${ }^{\mathrm{c}}$, H.-M. Montrieux ${ }^{\mathrm{a}}$, F. Delannay ${ }^{\mathrm{b}}$, J. Lecomte-Beckers ${ }^{\mathrm{a}}$ \\ a Université de Liège, Faculty of Applied Science, AEMM Department, Metallic Materials Science Unit, Belgium \\ ${ }^{\mathrm{b}}$ Université catholique de Louvain, Institute of Mechanics, Materials and Civil Engineering, Belgium \\ c Institut National des Sciences Appliquées de Lyon (INSA Lyon), MATEIS Laboratory, France
}

\section{A R T I C L E I N F O}

\section{Article history:}

Received 2 June 2015

Received in revised form 27 June 2015

Accepted 8 July 2015

Available online 9 July 2015

\section{Keywords:}

Mg alloys

Friction stir processing

Metal matrix composites

Mechanical properties

Microstructures

\begin{abstract}
A B S T R A C T
Short C fibres-Mg matrix composites have been produced by friction stir processing sandwiches made of a layer of $\mathrm{C}$ fabric stacked between two sheets of Mg alloy AZ31B or AZ91D. This novel processing technique can allow the easy production of large-scale metal matrix composites. The paper investigates the microstructure of FSPed C fibre-Mg composites in relation with the fragmentation of the $\mathrm{C}$ fibres during FSP and their influence on the tensile properties. 3D X-ray tomography reveals that the fibres orient like onion rings and are more or less fragmented depending on the local shear stress during the process. The fibre volume fraction can be increased from $2.3 \%$ to $7.1 \%$ by reducing the nugget volume, i.e. by using a higher advancing speed in AZ31B alloy or a stronger matrix alloy, like AZ91D alloy. A higher fibre volume fraction leads to a smaller grain size which brings about an increase of the composite yield strength by 15 to $25 \%$. However, a higher fibre volume fraction also leads to a lower fracture strain. Fracture surface observations reveal that damage occurs by fibre/matrix decohesion along fibres oriented perpendicularly to the loading direction.
\end{abstract}

\section{Introduction}

Magnesium alloys have attracted much attention over the last few years, mostly in view of applications where their low specific mass could be an advantage [1]. In particular, Mg matrix composites appear as possible substitutes for Al alloys [1-4]. Moreover, $\mathrm{Mg}$ matrix composites can present a better creep resistance than the unreinforced matrix alloy [4]. However, their production is faced with a number of challenges as well for the liquid routes as for the powder metallurgy route $[2,3,5,6]$. Friction Stir Processing (FSP) is a novel solid-state process that has developed recently based on the same principles as Friction Stir Welding (FSW) [7]. The method has now established itself as a very effective and versatile tool for modifying microstructure and, in particular, for processing MMCs in view of tailoring material properties $[8,9]$. The method for inserting the reinforcing phases in the matrix is an essential experimental parameter for the production of MMCs by FSP $[3,10]$. A number of different methods have been described in literature. They have been recently reviewed by Avettand-Fenoël et al. [10]. Particles or short fibres either have been deposited on the alloy surface

\footnotetext{
* Corresponding author at: Université de Liège, Faculty of Applied Science, A\&M Department, Metallic Materials Science Unit, Quartier Polytech 1, Allée de la Découverte 13A (B52/3), B 4000 Liège, Belgium.

E-mail address: anne.mertens@ulg.ac.be (A. Mertens).
}

[11] or have been placed in grooves $[4,10,12]$ or in holes [13]. Alternatively, particles have also been loaded in holes drilled in the FSP tool $[14,15]$. Experimental procedures are quite complex and there is always a risk that porosities remain in the composite [11].

A new, easier and much less labour intensive method for dispersing the reinforcing phase in the bulk of the composite has recently been devised by the present authors [16,17]. It consists in placing a layer of C fabric in between two sheets of $\mathrm{Mg}$ alloy and in subsequently applying FSP to this assembly, as schematically represented in Fig. 1. This processing route for the production of short fibre MMC could be extended to the production of larger structural parts. This new process has already been shown to lead to sound composites when optimizing FSP parameters (i.e. rotational and advancing speeds) [17]. Preliminary optical microscopy observations showed that FSP brings about a significant grain refinement [16,17], as a result of the high temperature and intense plastic deformation, which induce dynamic recrystallization and precipitate dissolution or coarsening [7-9,18]. The present work investigates the effect of the processing parameters on the fragmentation of the $C$ fabric into short $C$ fibres, along with its influence on microstructure evolution and on tensile properties after FSP. The process was used for producing C fibre reinforced composites, comparing two different $\mathrm{Mg}-\mathrm{Al}-\mathrm{Zn}$ matrix alloys with different strength. Alloy AZ31B is a fairly ductile single-phase $\alpha \mathrm{Mg}$ alloy, while alloy AZ91D is stronger but shows much less ductility. The paper analyses the fragmentation and the 

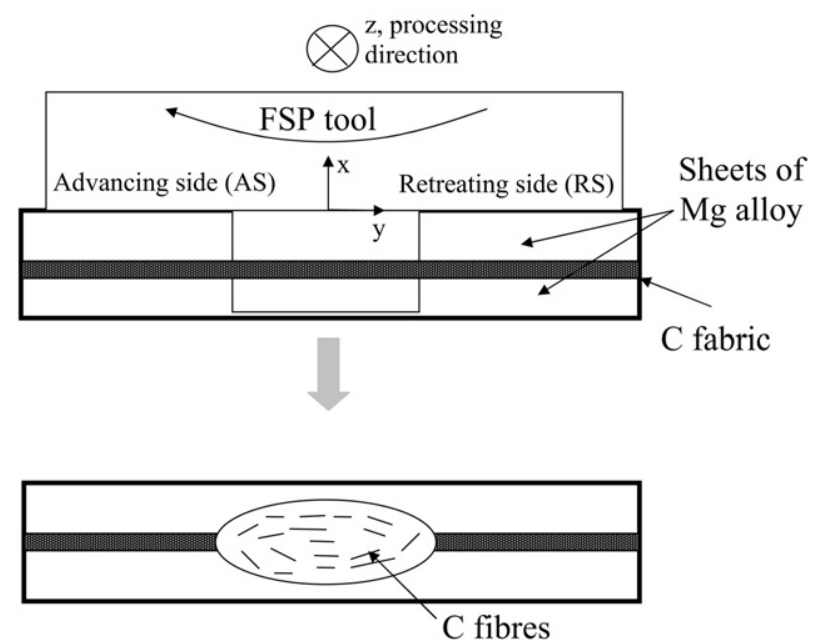

Fig. 1. Schematic representation of the method used for inserting the reinforcing phase into the substrate, with definition of the $x, y$ and $z$ directions. A layer of $C$ fibre fabric is stacked between two sheets of Mg alloy, and the resulting sandwich is friction stir processed to produce a composite reinforced with short $\mathrm{C}$ fibres.

orientation of the fibres in view to gain a deeper understanding of the influence of these parameters on grain size and on mechanical properties.

\section{Experimental procedure}

\subsection{Base materials}

The two $\mathrm{Mg}-\mathrm{Al}-\mathrm{Zn}$ alloys are commercial rolled sheets of alloy AZ31B, and as-cast plates of alloy AZ91D. Table 1 summarizes the alloy composition measured by inductively coupled plasma-optical emission spectroscopy (ICP-OES) along with their hardness. Small amounts of Mn are present in both alloys in order to fix Fe and other detrimental impurities into relatively harmless intermetallic precipitates [19]. The base material (BM) for alloy AZ31B exhibited more or less equiaxed $\alpha$-Mg grains (Fig. 2(a)). The as-cast plates AZ91D BM exhibited a two-phase microstructure with $\beta-\mathrm{Mg}_{17} \mathrm{Al}_{12}$ intermetallic precipitates coarsely distributed at the $\alpha$-Mg grain boundaries (Fig. 2(b)). Some porosity was present as casting defects. The reinforcing phase was inserted in the form of a Lyvertex ${ }^{\circledR} \mathrm{C}$ fabric produced by Carbone Lorraine, the characteristics of which are given in Table 2 [20].

\subsection{Processing conditions}

Friction stir processing was carried out under displacement control using a Hermle milling machine. The sample was a sandwich made by inserting one layer of $\mathrm{C}$ fibre fabric between two sheets of alloy AZ31B, or between two plates of alloy AZ91D (Fig. 1). The total thickness of the sandwich was always $3.5 \mathrm{~mm}$. The FS processing direction was perpendicular to the rolling direction of the sheets AZ31B. The FSP parameters were reproduced from a previous study that aimed at identifying the parameters ensuring a homogeneous distribution of the reinforcement [17]. The composites with matrix AZ31B were FSPed with a rotational speed of $1500 \mathrm{rpm}$ and an advancing speed of either $80 \mathrm{~mm} / \mathrm{min}$ or $300 \mathrm{~mm} / \mathrm{min}$. The composites with matrix

Table 1

Chemical composition (wt.\%), measured by ICP-OES, and hardness [HV10] of the two MgAl-Zn alloys.

\begin{tabular}{llllllllll}
\hline & $\mathrm{Al}$ & $\mathrm{Zn}$ & $\mathrm{Mn}$ & $\mathrm{Si}$ & $\mathrm{Ni}$ & $\mathrm{Fe}$ & $\mathrm{Cu}$ & $\mathrm{Mg}$ & Hardness [HV10] \\
\hline AZ31B & 2.85 & 0.73 & 0.45 & $<0.01$ & $<0.01$ & $<0.01$ & $<0.01$ & Bal. & $91.99 \pm 1.2$ \\
AZ91D & 8.95 & 0.59 & 0.16 & 0.04 & $<0.01$ & $<0.01$ & $<0.01$ & Bal. & $74.28 \pm 0.53$
\end{tabular}

(a)

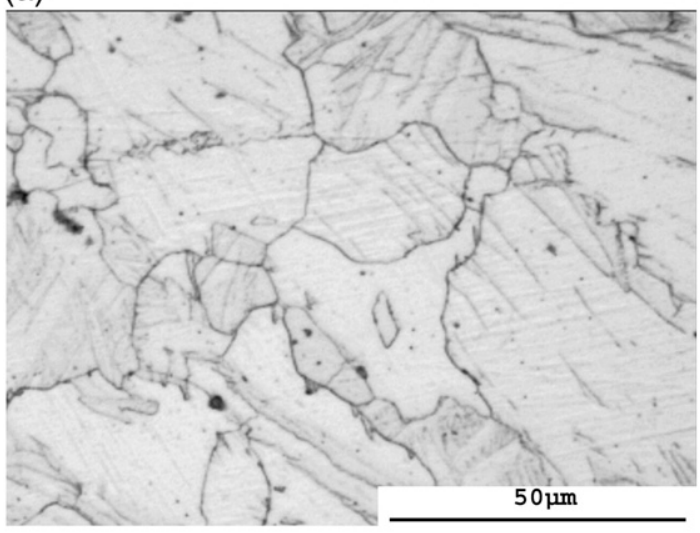

(b)

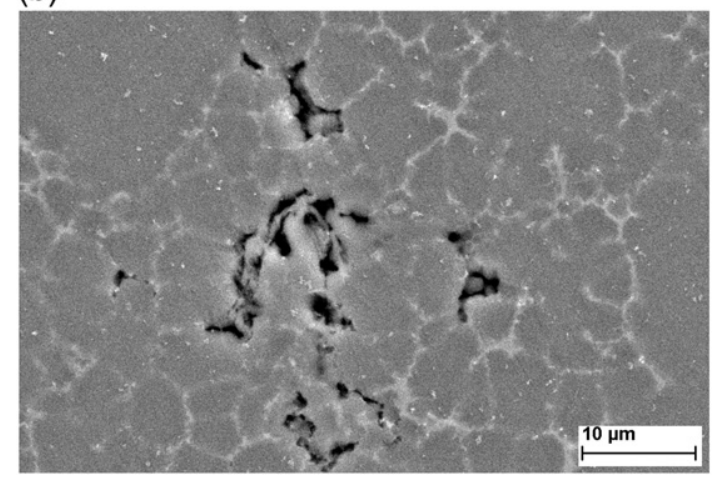

Fig. 2. Micrographs of base materials: (a) Optical micrograph of AZ31B after etching with a solution of $10 \mathrm{ml}$ of acetic acid, $4.2 \mathrm{~g}$ of picric acid, $10 \mathrm{ml}$ of deionized water and $70 \mathrm{ml}$ of ethanol and (b) SEM micrograph of AZ91D.

AZ91D were FSPed with a rotational speed of $500 \mathrm{rpm}$ and an advancing speed of $80 \mathrm{~mm} / \mathrm{min}$ (Table 3). Fig. 3 shows macrographs of the composites obtained according to these three sets of processing conditions. Use was made of a tool of $20 \mathrm{~mm}$ diameter with scrolled shoulder and a $6 \mathrm{~mm}$ diameter pin. The pin was $2.7 \mathrm{~mm}$ long and threaded with three flats (see Fig. 1 in [21]). The tool was tilted backwards by an angle of $1^{\circ}$. In order to obtain a sufficiently homogeneous distribution of the reinforcing phase in the nugget, three partially overlapping passes were carried out at $y=0 \mathrm{~mm}, y=-1.5 \mathrm{~mm}$ and $y=1.5 \mathrm{~mm}$ (see Fig. 1). An identical procedure was applied to reference samples consisting of two metal sheets without carbon fibre fabric inserted in between. Fig. 4 presents records of the tool temperature during the process. It shows that the temperature profiles are identical for the reference samples as for the composites.

\subsection{Microstructure characterisation}

The microstructure of the homogeneous nugget zone of the $\mathrm{C}-\mathrm{Mg}$ composites was characterised by optical microscopy and scanning electron microscopy (SEM). Samples for microstructural examination were polished following standard procedures. In some cases, they were etched with a solution of $10 \mathrm{ml}$ of acetic acid, $4.2 \mathrm{~g}$ of picric acid,

Table 2

Characteristics of the $\mathrm{C}$ fibre fabric used as reinforcing phase [20].

\begin{tabular}{lllll}
\hline $\begin{array}{l}\text { Thickness } \\
(\mathrm{mm})\end{array}$ & $\begin{array}{l}\text { Fibre volume } \\
\text { fraction }(\%)\end{array}$ & $\begin{array}{l}\text { Fibre density } \\
\left(\mathrm{g} / \mathrm{cm}^{3}\right)\end{array}$ & $\begin{array}{l}\text { Fibre diameter } \\
(\mu \mathrm{m})\end{array}$ & $\begin{array}{l}\text { Young's } \\
\text { modulus } \\
(\mathrm{GPa})\end{array}$ \\
\hline 0.52 & $30-35$ & 1.74 & 7 & 230 \\
\hline
\end{tabular}


Table 3

Average grain size as a function of processing conditions for $\mathrm{C}$ fibres-Mg composites and for reference samples.

\begin{tabular}{lllll}
\hline Material & AZ31B & & AZ91D \\
\cline { 3 - 4 } \cline { 5 - 6 } $\begin{array}{llll}\text { Processing } \\
\text { parameters }\end{array}$ & $80 \mathrm{~mm} / \mathrm{min}$, & $300 \mathrm{~mm} / \mathrm{min}$, & & $80 \mathrm{~mm} / \mathrm{min}$, \\
\hline Without C fibres & $1500 \mathrm{rpm}$ & $1500 \mathrm{rpm}$ & & $500 \mathrm{rpm}$ \\
\hline With C fibres & $12.9 \pm 4.0 \mu \mathrm{m}$ & $16.4 \pm 5.6 \mu \mathrm{m}$ & & $9.3 \pm 3.1 \mu \mathrm{m}$ \\
\hline
\end{tabular}

$10 \mathrm{ml}$ of deionized water and $70 \mathrm{ml}$ of ethanol [22], in order to reveal the grain structure.

The size distribution and the local orientation of the fibres in the composite have been analysed by 3D X-ray tomography using a laboratory equipment with a procedure already described in detail in Buffiere et al. [23]. Given the small size of the particles and the faint attenuation contrast between $\mathrm{C}$ and $\mathrm{Mg}$, special care has been taken in the imaging conditions. The transmission X-ray tube (W target) was operated at a low accelerating voltage $(50 \mathrm{kV})$ and high intensity $(275 \mu \mathrm{A})$. The size of the X-ray spot in these conditions is about $1.5 \mu \mathrm{m}$. The number of projections was 900 and the exposure time for each radiograph was $2 \mathrm{~s}$. To overcome saturation, each radiograph was an average of 3 exposures of $667 \mathrm{~ms}$ each. The voxel size was set at $1.6 \mu \mathrm{m}$.

In order to improve the counting statistics and signal to noise ratio in the reconstruction and to reduce the ring artefacts, a new "scan averaging" procedure was also adopted in this work. Three similar scans of each sample were acquired, the sample being physically translated of $30 \mu \mathrm{m}$ along the rotation axis between each scan. These three scans were then registered back and combined by an arithmetic averaging of the grey level of each voxel. The boxes' cross-section sizes were $320 \mu \mathrm{m} \times 320 \mu \mathrm{m}$ and $1.6 \mathrm{~mm}$ long for each sample. 6 boxes were extracted for composite AZ91D and 16 boxes for composite AZ31B. Fig. 5 shows a 3D visualization of the segmented fibres in a portion of these boxes, i.e. in one of the five sub-boxes of size $320 \mu \mathrm{m} \times 320 \mu \mathrm{m} \times 320 \mu \mathrm{m}$.

The tomography data were treated in order to extract the fibre geometry and orientation. This treatment is rather similar to the one in Landron et al. [24]. It includes segmentation of the grey level images to obtain a binary image, then labelling of this segmented image. After labelling, each cluster of connected voxels has different grey level and

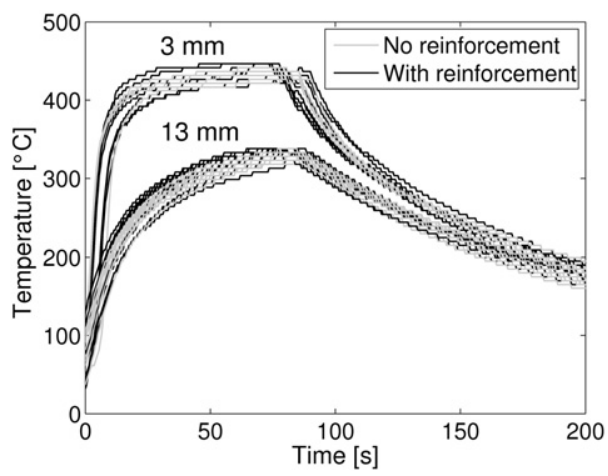

Fig. 4. Temperature profiles recorded upon processing composites AZ91D and reference samples, using two thermocouples inserted in the tool centre at distances of $3 \mathrm{~mm}$ and $13 \mathrm{~mm}$ from the shoulder, respectively. The processing parameters are an advancing speed of $80 \mathrm{~mm} / \mathrm{min}$ and a rotational speed of $500 \mathrm{rpm}$.

it becomes easy to measure the morphology of each cluster (i.e. each fibre fragment). The inertia momentum and corresponding length, diameter and orientation of each fibre fragment can thus be measured. Only the particles presenting a diameter larger than $4 \mu \mathrm{m}$ and smaller than $11 \mu \mathrm{m}$, thus reflecting the initial narrow diameter distribution of the fibres around a mean value of $7 \mu \mathrm{m}$ (Table 2), as well as a shape factor (i.e. length/diameter ratio) larger than 1.5 were analysed. This allowed to extract and analyse the larger pieces of fibres and to exclude the background noise. However, it has for consequence to eliminate smaller fibre fragments from the analysis. A sensibility analysis showed that these parameters provide the best compromise between loss of data and treatment of the noise in the 3D images. It is believed that the orientation of the larger fragments is representative of the population. The orientation of the fibres was then determined with respect to the coordinate system according to the definitions in Fig. 1.

\subsection{Mechanical tests}

Vickers hardness (10 kg) was measured in the centre of the nugget on the transverse section of the samples (i.e. plane $(x, y)$ ). Two or three specimens per condition of production were tensile tested. The

(a) AZ31B, $80 \mathrm{~mm} / \mathrm{min}$ and $1500 \mathrm{rpm}$

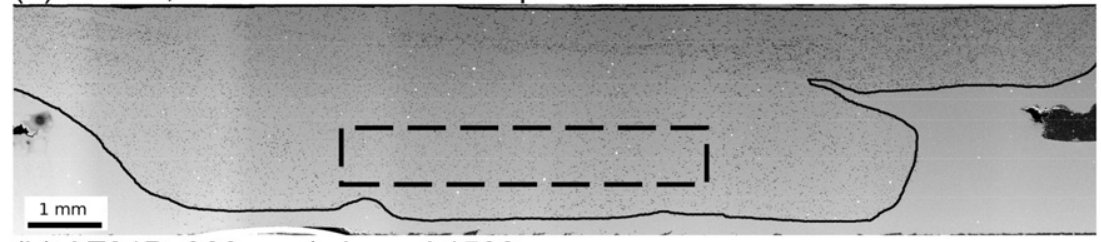

(b) $\mathrm{AZ31B}, 300 \mathrm{~mm} / \mathrm{min}$ and $1500 \mathrm{rpm}$

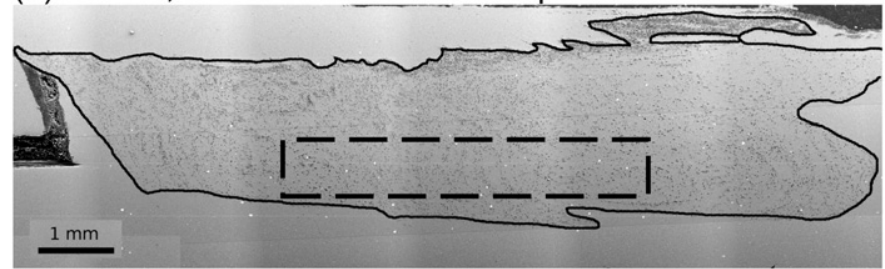

(c) AZ91D, $80 \mathrm{~mm} / \mathrm{min}$ and $500 \mathrm{rpm}$

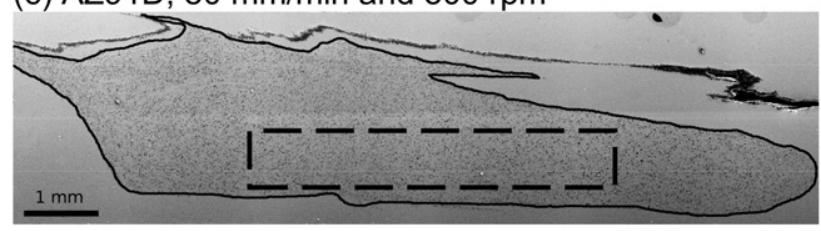

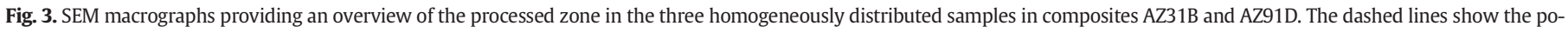
sitions where the tensile specimens were machined in the homogeneous nugget zone of the FSPed samples. 


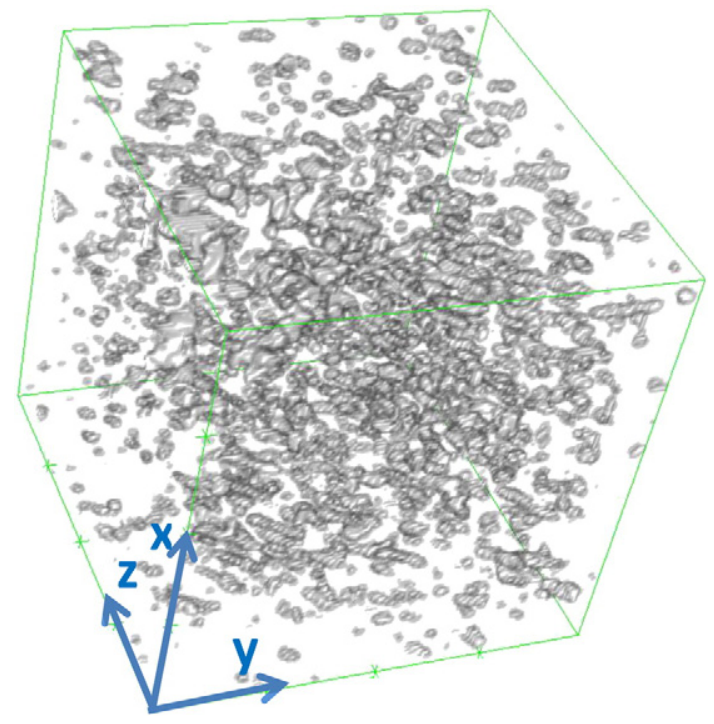

Fig. 5. 3D view of a treated cubic X-ray tomography sub-box of edge size $320 \mu \mathrm{m}$ for the composite AZ31B-300 mm/min. Five of such sub-boxes in the $z$ direction (with the same $(x, y)$ position of their centre) are used to obtain the fibre orientation at a given $(x, y)$ position. In the supplementary materials, available on the internet, a movie shows various views of this sub-box.

tensile specimens were $0.8 \mathrm{~mm}$ thick, $5 \mathrm{~mm}$ wide and $60 \mathrm{~mm}$ long, with an initial gauge length equal to $22 \mathrm{~mm}$. As indicated by the dashed lines in the macrographs of Fig. 3, they were machined in the homogeneous nugget zone of the FSPed material. The tensile specimens were systematically verified under optical microscopy to ensure that they had been correctly extracted from the composite zone. Strain gauges were stuck on both sides of the tensile specimens for the measurement of the Young's modulus.

(a)

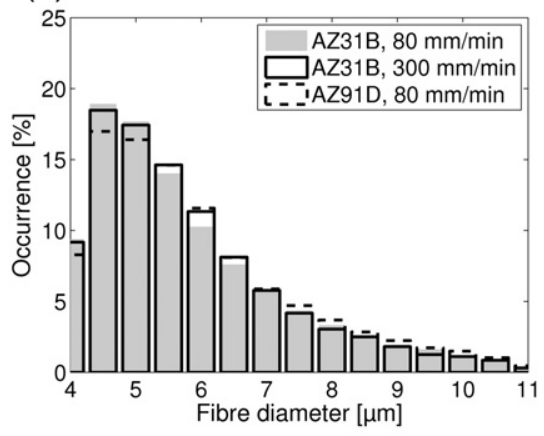

(c)

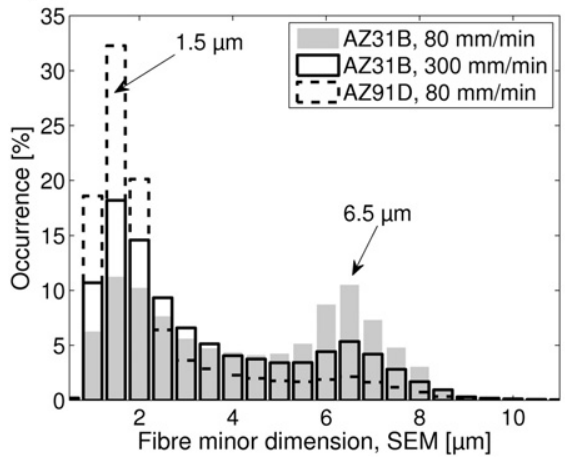

\section{Results and discussion}

\subsection{Microstructure}

\subsubsection{Fibre size distribution}

The $C$ fibre size distribution was characterised by X-ray tomography and SEM image analysis. Fig. 6(a-c) show the fibre diameter distribution for all three composites investigated. The minor axis of an equivalent ellipsoid is considered to correspond closely to the diameter provided by X-ray tomography. Fig. 6(a,b) shows the fibre diameter distribution for fibres presenting a diameter larger than $4 \mu \mathrm{m}$, which is the cut-off diameter for the X-ray tomography images due to the lower resolution of that technique (Section 2.3). A similar distribution is found for the three composites investigated. The mean diameter of the distribution provided by the X-ray tomography data was $5.8 \mu \mathrm{m}$ in the three composites (Table 4). The SEM image analysis of fibres larger than $4 \mu \mathrm{m}$ in diameter reveals a slightly larger mean diameter (6$6.3 \mu \mathrm{m}$ ), which is rather similar for the three composites investigated. The small difference between SEM images and X-ray tomography results may be explained by the slightly arbitrary choice of grey level threshold for the fibre identification. These diameters are slightly lower than the nominal diameter of $7 \mu \mathrm{m}$ announced for the fabric (according to Table 2). They reflect some erosion of the fibres during processing, which may also be related to the observation of small fragments of $C$ fibres in the matrix (Fig. 7, and particularly Fig. 7(b)). Fig. 6(c) presents the diameter distribution resulting from the whole SEM image analysis (i.e. below and above $4 \mu \mathrm{m}$ ). The resulting bimodal distribution in fibre diameter clearly shows that there are either fibres with a diameter slightly below the initial $7 \mu \mathrm{m}$ diameter and, in addition, debris resulting from the erosion of the fibres that have a typical size around $1.5 \mu \mathrm{m}$. Fig. 6 (c) also shows that the proportion of debris is larger in composite AZ31B processed at $300 \mathrm{~mm} / \mathrm{min}$ compared to composite AZ31B processed at $80 \mathrm{~mm} / \mathrm{min}$. Composite AZ91D presents the largest proportion of such small debris.

(b)

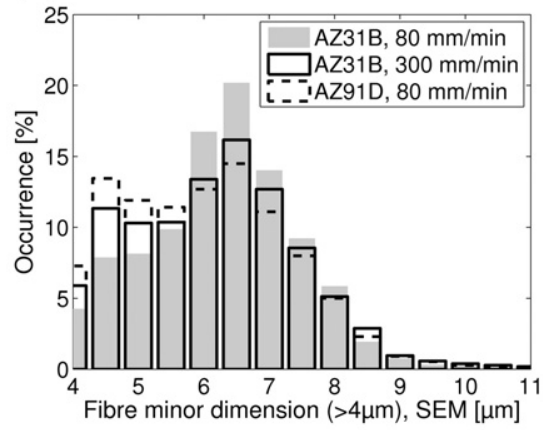

(d)

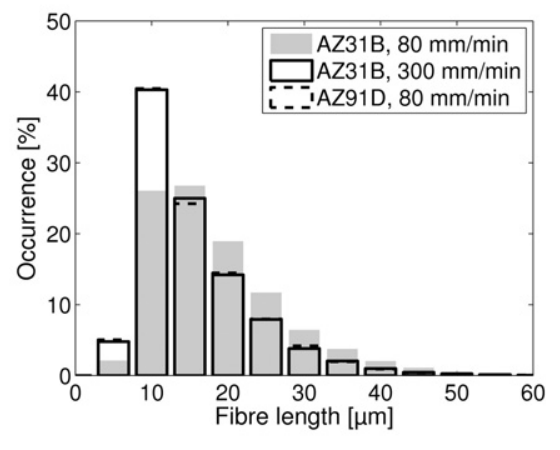

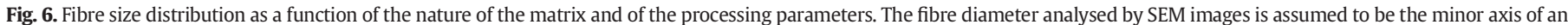

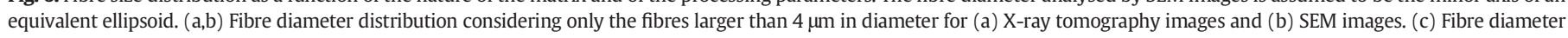
distribution considering all fibres (from SEM images). (d) Fibre length distribution for X-ray tomography images. 
Table 4

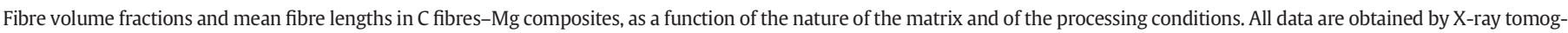

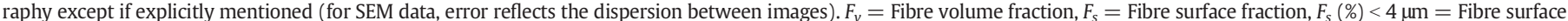

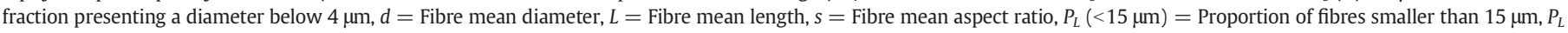
$(>30 \mu \mathrm{m})=$ Proportion of fibres larger than $30 \mu \mathrm{m}$.

\begin{tabular}{|c|c|c|c|c|c|c|c|c|c|}
\hline Mg alloy & Processing conditions & $F_{S}(\%)(\mathrm{SEM})$ & $F_{s}(\%)<4 \mu \mathrm{m}(\mathrm{SEM})$ & $F_{v}(\%)$ (i.e. $>4 \mu \mathrm{m}$ ) & $d(\mu \mathrm{m})$ & $L(\mu \mathrm{m})$ & $S$ & $P_{L}(<15 \mu \mathrm{m})(\%)$ & $P_{L}(>30 \mu \mathrm{m})(\%)$ \\
\hline \multirow[t]{2}{*}{ AZ31B } & 80 mm/min, 1500 rpm & $2.3 \pm 0.3$ & 0.3 & 1.8 & 5.8 & 18.6 & 3.2 & 42.5 & 10.8 \\
\hline & $300 \mathrm{~mm} / \mathrm{min}, 1500 \mathrm{rpm}$ & $3.6 \pm 0.5$ & 1.0 & 1.6 & 5.8 & 15.5 & 2.7 & 59.5 & 5.6 \\
\hline AZ91D & $80 \mathrm{~mm} / \mathrm{min}, 500 \mathrm{rpm}$ & $7.1 \pm 0.5$ & 2.4 & 2.5 & 5.8 & 15.6 & 2.7 & 59.4 & 5.3 \\
\hline
\end{tabular}

Fig. 6(d) presents the fibre length distribution in the three composites. This can only be investigated by X-ray tomography. Table 4 provides the mean length and proportion of fibres smaller than $15 \mu \mathrm{m}$ and larger than $30 \mu \mathrm{m}$. Composite AZ31B processed at $300 \mathrm{~mm} / \mathrm{min}$ exhibits $\sim 40 \%$ more short fibres $(<15 \mu \mathrm{m})$ and half the proportion of larger fibres $(>30 \mu \mathrm{m})$ compared to the AZ31B composite processed at $80 \mathrm{~mm} / \mathrm{min}$ (Table 4). This translates into a reduction of mean fibre length by a factor of about 1.2 (Table 4). The reduction in fibre length (Fig. 6(d)) and the presence of more debris of fibres (Fig. 6(c)) can be ascribed to the higher shear strains associated to the lower maximum temperature at higher advancing speed. Fig. 6(d) and Table 4 show that the length distribution is similar in composite AZ91D as in composite AZ31B processed with a speed of $300 \mathrm{~mm} / \mathrm{min}$. The proportion of small fibres $(\sim 60 \%)$ and large fibres $(\sim 5 \%)$ is also very similar for those two cases (Table 4). Owing to the higher strength of alloy AZ91D and to the lower temperature associated to the lower rotational speed, fibre length is lower in composite AZ91D than in composite AZ31B processed with the same advancing speed of $80 \mathrm{~mm} / \mathrm{min}$. This difference is particularly evidenced in the proportion of large particles $(>30 \mu \mathrm{m})$,
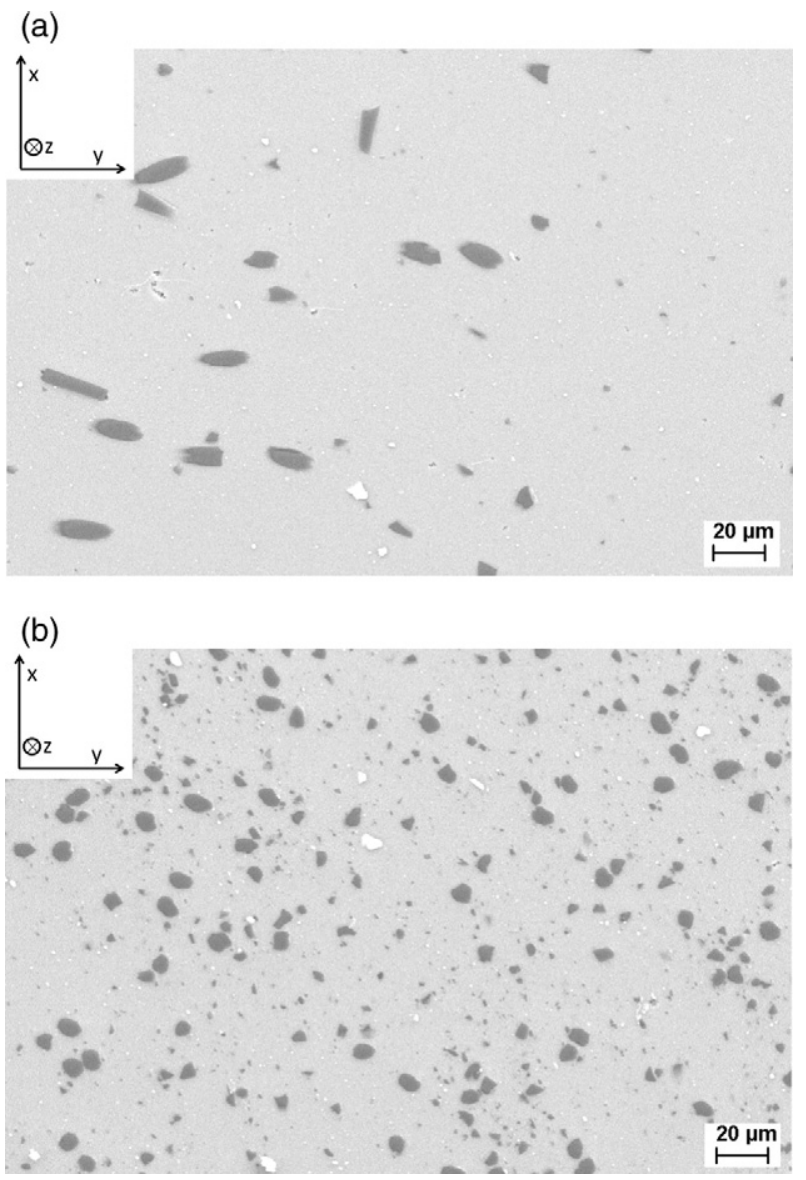

Fig. 7. SEM micrographs of composites AZ31B processed at a rotational speed of $1500 \mathrm{rpm}$ and (a) an advancing speed of $80 \mathrm{~mm} / \mathrm{min}$, and (b) an advancing speed of $300 \mathrm{~mm} / \mathrm{min}$. The $\mathrm{x}, \mathrm{y}$ and $\mathrm{z}$ directions corresponding to the FSP process (Fig. 1) are provided in the inset. which is twice larger in composite AZ31B processed at $80 \mathrm{~mm} / \mathrm{min}$ (Table 4) than in composite AZ91D. The presence of a larger amount of debris $(\sim 1.5 \mu \mathrm{m}$ in size) in alloy AZ91D is also a sign of the influence of the stronger matrix on the fibre erosion during FSP. The average fibre aspect ratio is close to 3 in all three composites (Table 4) and it was found to be very little dependent on position inside the nugget.

\subsubsection{Volume fraction of $C$ fibres}

The nugget extension and the volume fraction of the $\mathrm{C}$ fibres have been determined using SEM combined with image analysis (Table 4). The macrographs of Fig. 3( $a$ and b) show that, in composite AZ31B, the nugget spreads over a wider volume when the advancing speed is lower. This broadening of the processing zone for decreasing advancing speeds is due to the increase of the heat input when the advancing speed is lower. This effect has been previously reported by Lee et al. [25] during FSW of alloy AZ31B and more recently by Razal Rose et al. [26] upon FSW of alloy AZ61A. Fig. 3(c) shows that the nugget zone extension is even smaller in composite AZ91D which was processed with an advancing speed of $80 \mathrm{~mm} / \mathrm{min}$ but with a rotational speed of $500 \mathrm{rpm}$. A smaller nugget volume brings about a distribution of the reinforcing phase over a smaller volume, which leads to a higher fibre volume fraction. This effect can be observed on the SEM micrographs of Fig. 7. Table 4 presents the fibre surface fraction in the three composites measured by SEM combined with image analysis: the surface fraction is lower in composite AZ31B processed at $80 \mathrm{~mm} / \mathrm{min}$ (Fig. 7(a)) than in the same composite processed at $300 \mathrm{~mm} / \mathrm{min}$ (Fig. 7(b)) and the highest surface fraction is measured in composite AZ91D. Consistently, surface fractions measured by SEM are roughly proportional to the inverse of the area of the nugget size measured on the macrographs (Fig. 8).

$\mathrm{X}$ ray tomography measurements largely underestimate the fibre surface fraction measured by SEM (Table 4). This underestimation is due to the lower resolution of $\mathrm{X}$ ray tomography, which cannot take account of the smaller fragments of $C$ fibres. Table 4 provides the surface fraction of fibres presenting a diameter below $4 \mu \mathrm{m}$, as identified from SEM image analysis. This confirms that a large proportion of fibres are below the resolution of X-ray tomography and that this proportion depends on the processing parameters and the matrix material as discussed in Section 3.1.1.

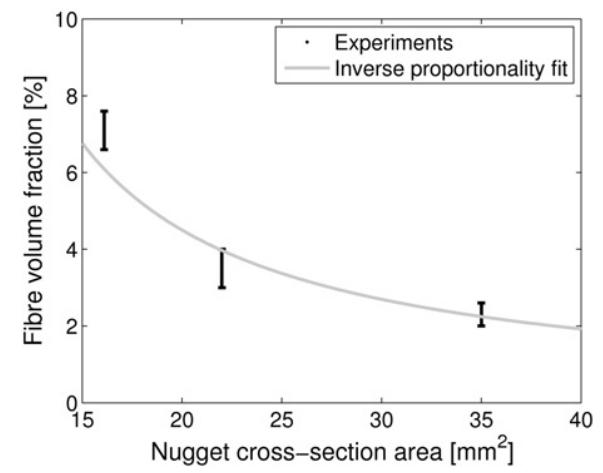

Fig. 8. Fibre volume fraction (data from SEM image analysis, Table 4) as a function of the nugget cross-section area (measured on the macrographs in Fig. 3). The fitting curve shows a tendency to inverse proportionality. 
(a)

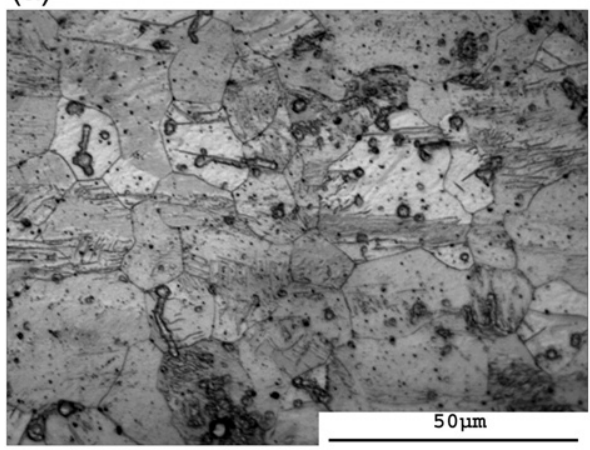

(c)

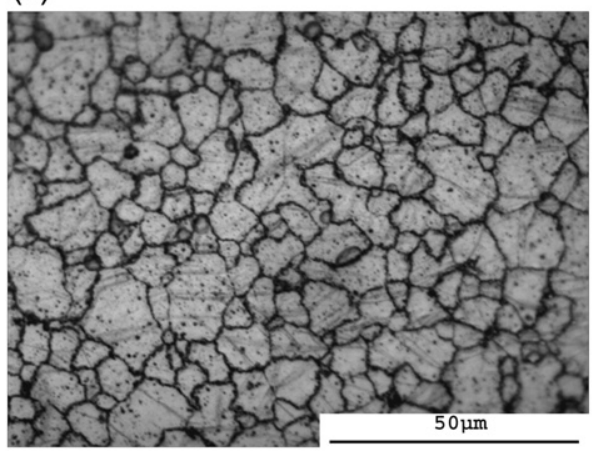

(b)

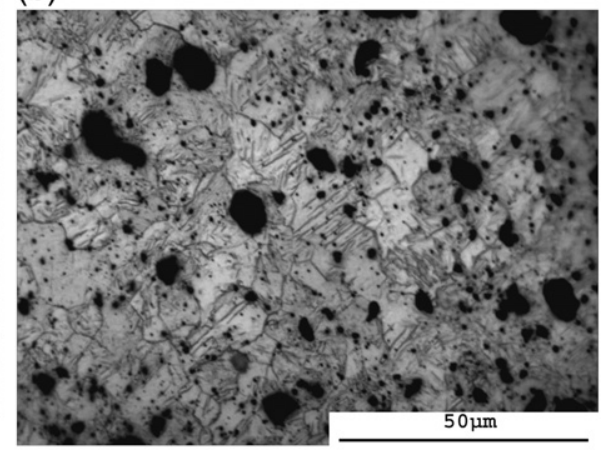

(d)

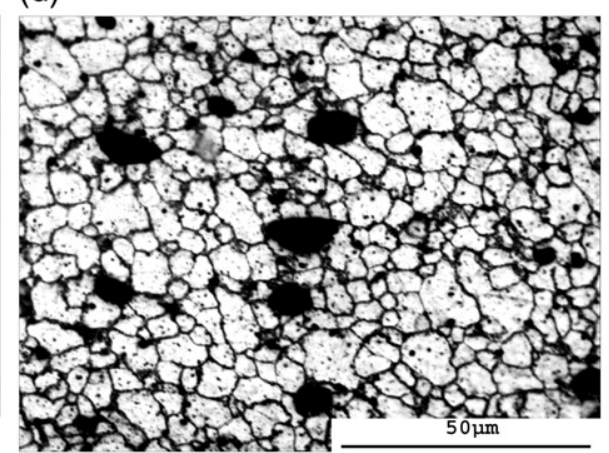

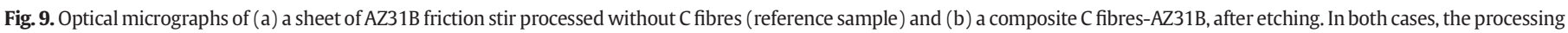

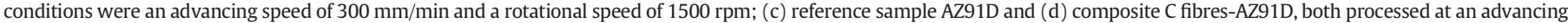
speed of $80 \mathrm{~mm} / \mathrm{min}$ and a rotational speed of $500 \mathrm{rpm}$ after etching. The black dots in figures (b) and (d) are carbon fibres.

\subsubsection{Matrix grain size}

FSP was originally developed as a way to bring about microstructural modifications such as grain refinement induced by dynamic recrystallization [4,7-10]. The matrix grain size in the composites was observed on etched samples, and compared with the grain size in the base material and in the reference samples (Fig. 9 and Table 3). The grain size in composites AZ31B is $20 \%$ and $40 \%$ lower than in the corresponding FSPed reference samples for the advancing speed of $80 \mathrm{~mm} / \mathrm{min}$ and $300 \mathrm{~mm} / \mathrm{min}$, respectively. Similarly, the grain size in composite AZ91D is 33\% lower than in the reference sample. This is consistent with previous literature reports on FSP composites $[4,10]$. It can be ascribed to the following.

- Particle stimulated nucleation (PSN) of a new grain at a pre-existing sub-grain in the deformation zone surrounding a particle [27],

- and to the restraining of grain growth by the particles after recrystallization during the cooling stage [10].

The smaller average grain size in composites AZ31B and AZ91D appears to be related to the difference in fibre volume fraction between the composites, depending on the advancing speeds (Table 4). Indeed, a larger fibre volume fraction is expected to lead to a more efficient PSN and to a more efficient pinning of the grain boundaries during the cooling stage. In composites AZ31B, the larger proportion of shorter fibres at higher advancing speed brings about a slightly smaller grain size after processing at an advancing speed of $300 \mathrm{~mm} / \mathrm{min}$ (Table 3).

\subsubsection{Fibre orientation}

X-ray tomography also allowed obtaining the local distribution of fibre orientations. This is an original result as the only FSPed metal matrix composite analysed in the literature concerns non-elongated particles (i.e. SiC particles) [28]. Figs. 10 and 11 show the results of such measurements in composite AZ31B processed at $300 \mathrm{~mm} / \mathrm{min}$. (a)

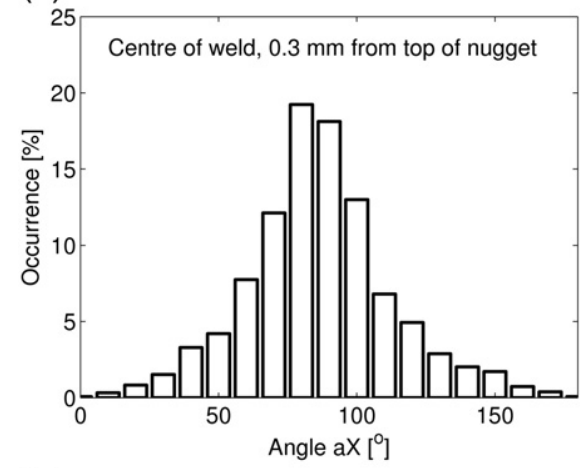

(b)

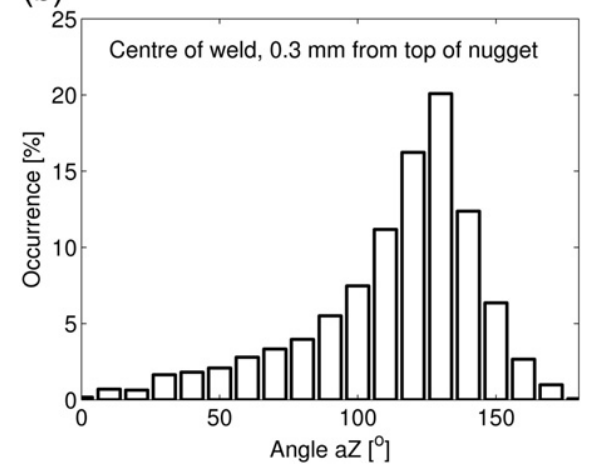

Fig. 10. Distribution of (a) angle $a X$ (angle between the main axis of the fibre and the $x$-axis) and (b) angle $a Z$ (angle between the main axis of the fibre and the z-axis) in the centre of the processed zone $(y=0)$ at $0.3 \mathrm{~mm}$ from the top of the nugget obtained by the analysis of 3D X-ray tomography performed on composites AZ31B processed with an advancing speed of $300 \mathrm{~mm} / \mathrm{min}$. 


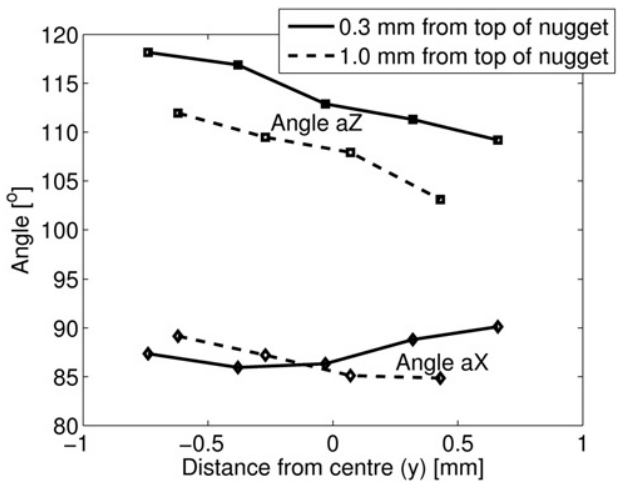

Fig. 11. Evolution of the mean angles $a X$ and $a Z$ as a function of the transverse $(y)$ position at $0.3 \mathrm{~mm}$ and $1 \mathrm{~mm}$ from the top of the nugget for composite AZ31B processed with an advancing speed of $300 \mathrm{~mm} / \mathrm{min}$.

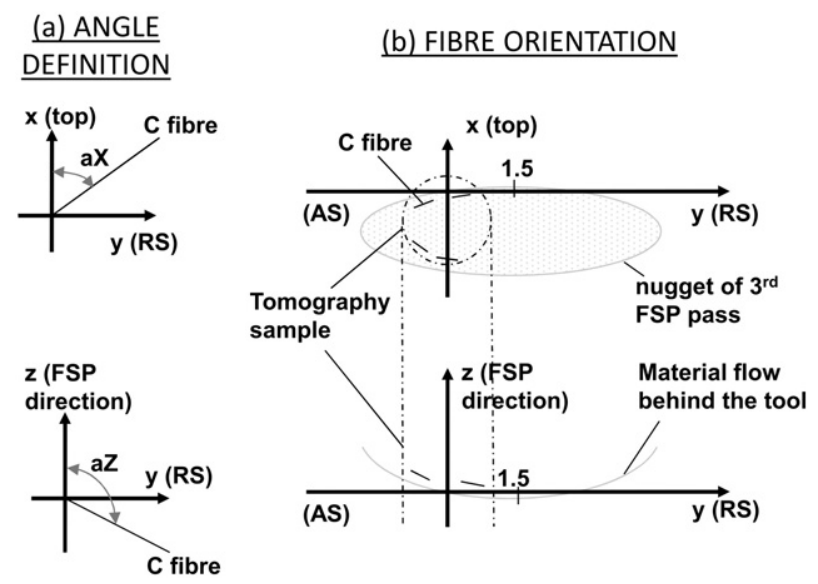

Fig. 12. Scheme explaining (a) the angle definition and (b) the fibre orientation in a composite material after the last processing pass. The centre of the tool during this last pass is located at $y=1.5 \mathrm{~mm}$. The top scheme represents the $(x, y)$ transverse section with the light grey dotted ellipse representing the nugget of the last processing pass (i.e. third pass). The bottom scheme represents the $(y, z)$ plane as viewed from the top of the processed zone. The light grey curved line represents the feature observed on the top surface of a processed zone.

The analysed volume is composed of 16 square boxes of cross-section $320 \mu \mathrm{m} \times 320 \mu \mathrm{m} \times 1.6 \mathrm{~mm}$. Fig. 12 shows a scheme of the fibre orientations across the nugget in planes $(x, y)$ and $(z, y)$ together with the definition of the angles: $a X$ is the angle between the axis of the fibre and the $x$-coordinate axis and $a Z$ is the angle between the axis of the fibre and the $z$-coordinate axis. AS and RS designate the advancing side and the retreating side of the tool. Fig. 10 shows the distribution of angles $a X$ and $a Z$ when the box is located in the centre of the nugget $(y=0)$ at $0.3 \mathrm{~mm}$ from the top of the specimen (in the $x$ direction). Fig. 11 shows the variation of the average of angles $a X$ and $a Z$ as a function of the transverse position when the box is located either at $0.3 \mathrm{~mm}$ or at $1 \mathrm{~mm}$ from the top surface of the sample. For a fibre oriented along the $y$-axis, the angles $a X$ and $a Z$ are equal to $90^{\circ}$. Hence, Figs. 10 and 11 show that, at $0.3 \mathrm{~mm}$ and at $1 \mathrm{~mm}$ from the top, the fibres are oriented close to the $y$-axis. According to Fig. 11, the mean of angle $a X$ is slightly lower than $90^{\circ}$ and slightly increases with increasing $y$ (at least at $0.3 \mathrm{~mm}$ from the top). This reflects the general orientation of the fibres like onion rings which can be observed at low magnification in the nugget of the third FSP pass. In contrast, angle $a Z$ is larger than $90^{\circ}$ and it decreases when $y$ increases. This indicates that the fibres orient in parallel with the circular flow of the material under the action of the tool.

As the fibres in the initial fabric are divided in equal parts between orientations $\left(a X=90^{\circ}, a Z=90^{\circ}\right)$ and $\left(a X=90^{\circ}, a Z=0^{\circ}\right)$, it could have been expected to find a bi-modal angular distribution of angle $a Z$. This is not observed: fibre orientation is entirely determined by the material flow field during FSP.

\subsection{Mechanical properties}

\subsubsection{Young's modulus}

The Young's modulus values measured by means of strain gauges during tensile testing are given in Tables 5 and 6. All FSPed samples, whether the composites or the reference samples, present a very similar Young's modulus close to $44 \mathrm{GPa}$. Within the experimental accuracy, this value is close to the value of $45 \mathrm{GPa}$ commonly reported for alloys AZ31B [29] and AZ91D [30].

Using a simple shear lag model [31], the Young's modulus of a short fibre composite $E_{c}$ can be evaluated as follows:

$E_{c}=f_{v} E_{f}\left[1-\frac{\tanh (n s)}{n s}\right]+\left(1-f_{v}\right) E_{M}$

where $E_{f}$ is the Young's modulus of the fibre equal to $230 \mathrm{MPa}$ (see Table 2), $E_{M}$ is the Young's modulus of the matrix, i.e. magnesium, equal to $45 \mathrm{GPa}$ [29,30], $s$ is the fibre aspect ratio equal to 2.7 or 3.2 depending on the samples (see Table 4 ) and $n$ is given by the following expression [31]:

$n=\sqrt{\frac{2 E_{M}}{E_{f}\left(1+\nu_{M}\right) \ln \left(1 / f_{v}\right)}}$

where $\nu_{M}$ is Poisson's ratio of the matrix equal to 0.35 . This leads to the Young's modulus of the composite insignificantly different from the Young's modulus of magnesium as reported in Tables 5 and 6. At least, the fact that measured Young's moduli are close to the values predicted by a shear lag model is an indication that FSPed specimens are devoid of porosity.

\subsubsection{Plastic properties}

Fig. 13 presents true stress versus true strain curves of the FSPed composites and reference samples. Hardness and tensile properties are provided in Tables 5 and 6 for samples AZ31B and AZ91D, respectively.

Tensile curves of FSP samples exhibit an S-shape that typically attests for the activation and extension of $\{10 \overline{1} 2\}$ twinning during tensile straining $[32,33]$. This is consistent with numerous previous reports according to which FSP induces a strong texturing of Mg alloys [see e.g. 18, 34-37]. It has been shown that the basal plane generally tends to orient along the material flow. In the centre of the nugget zone (i.e. where the tensile specimens have been extracted), the basal plane is perpendicular

Table 5

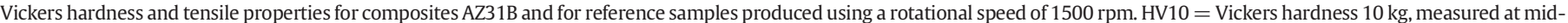

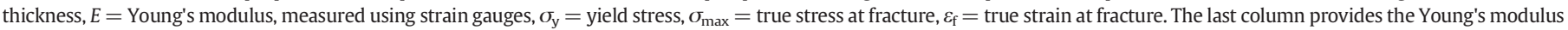
of the composites as predicted by the shear lag model (Eq. (1)).

\begin{tabular}{|c|c|c|c|c|c|c|c|}
\hline FSP parameters & & HV10 & $E[\mathrm{GPa}]$ & $\sigma_{\mathrm{y}}[\mathrm{MPa}]$ & $\sigma_{\max }[\mathrm{MPa}]$ & $\varepsilon_{\mathrm{f}}$ & $E[\mathrm{GPa}]$ predicted by shear lag model \\
\hline \multirow[t]{2}{*}{ Without C fibres } & $80 \mathrm{~mm} / \mathrm{min}$ & $54.3 \pm 0.8$ & $44 \pm 4$ & $67 \pm 5$ & $269 \pm 12$ & $0.187 \pm 0.005$ & / \\
\hline & $300 \mathrm{~mm} / \mathrm{min}$ & $55.0 \pm 1.8$ & $42 \pm 4$ & $74 \pm 1$ & $265 \pm 1$ & $0.149 \pm 0.001$ & / \\
\hline \multirow[t]{2}{*}{ With C fibres } & $80 \mathrm{~mm} / \mathrm{min}$ & $61.1 \pm 0.8$ & $41 \pm 3$ & $77 \pm 4$ & $237 \pm 11$ & $0.115 \pm 0.007$ & 45.0 \\
\hline & $300 \mathrm{~mm} / \mathrm{min}$ & $62.3 \pm 1.6$ & $46 \pm 4$ & $87 \pm 5$ & $168 \pm 1$ & $0.051 \pm 0.004$ & 44.8 \\
\hline
\end{tabular}


Table 6

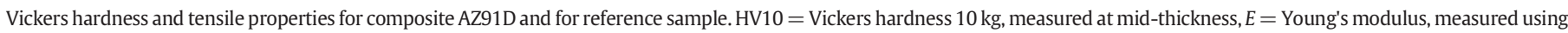

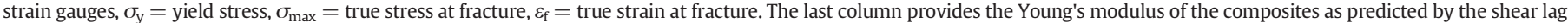
model (Eq. (1)).

\begin{tabular}{|c|c|c|c|c|c|c|}
\hline & HV10 & $E$ [GPa] & $\sigma_{\mathrm{y}}[\mathrm{MPa}]$ & $\sigma_{\max }[\mathrm{MPa}]$ & $\varepsilon_{\mathrm{f}}$ & $E[\mathrm{GPa}]$ predicted by shear lag model \\
\hline Without C fibres & $75.8 \pm 0.9$ & $44 \pm 1$ & $124 \pm 4$ & $329 \pm 68$ & $0.110 \pm 0.051$ & / \\
\hline With C fibres & $89.3 \pm 1.2$ & $43 \pm 1$ & $156 \pm 6$ & $280 \pm 23$ & $0.069 \pm 0.023$ & 45.1 \\
\hline
\end{tabular}

to the tool advance direction whereas the c-axis is parallel to this direction (which is the specimen tensile direction). Such an orientation is known to be favourable for the occurrence of $\left\{\begin{array}{lll}10 & 1 & 2\end{array}\right\}$ twinning [33, 35,38 ], which brings about a low critical resolved shear stress [34]. For FSPed AZ31B samples without C fibres, the high strain hardening ability exhibited at higher strains (Fig. 13) is consistent with the behaviour reported by Agnew et al. [32] for equal channel angular processed AZ31B deforming by twinning, and by Yuan et al. [33] for FSP AZ31-H24. This behaviour has been attributed to various mechanisms: (i) twininduced grain refinement [33], (ii) transformation of dislocations from glissile to sessile [33] and (iii) the fact that twinning re-orients portions of the crystallites into hard orientation, hence giving rise to rapid and sustained hardening $[29,32]$.

With respect to the FSPed reference samples, the addition of the carbon fibres brings about an increase of the yield stress and of the hardness of the nugget

- by $15-18 \%$ and $13 \%$, respectively, for composites AZ31B (Table 5 ) - and by $26 \%$ and $18 \%$, respectively, for composites AZ91D (Table 6).

In the case of $A Z 31 \mathrm{~B}$, when the advancing speed increases from $80 \mathrm{~mm} / \mathrm{min}$ to $300 \mathrm{~mm} / \mathrm{min}$, the yield stress increases by 7-10 MPa both in the composites and the FSPed reference samples (Table 5 and Fig. 13). As shown in Section 3.1.3, a higher advancing speed gives rise to a smaller average grain size in the composite (Table 3), which brings about higher yield strength. The higher strength of the composite materials compared to the reference samples can also be ascribed to the grain refinement associated to the presence of the fibres (Table 3). However, the variation of the yield strength of the FSPed samples does not exactly follow the classical Hall-Petch law. Indeed, reference specimens processed with different advancing speeds exhibit different values of the yield stress in spite of their very similar grain size. This suggests that local textural effects related to changes in the dynamic recrystallization processes as a function of the advancing speed may play a role in the deformation $[25,35]$. The beneficial effect of the addition of carbon fibres on the yield strength and hardness is thus demonstrated.

In contrast to the yield strength, a change of the advancing speed seems to have a more limited impact on the hardness. Indeed, if the material presents a high strain hardening ability, hardness is related more to the ultimate tensile strength than to the yield strength [39]. For the composite specimens, as discussed in the following section,

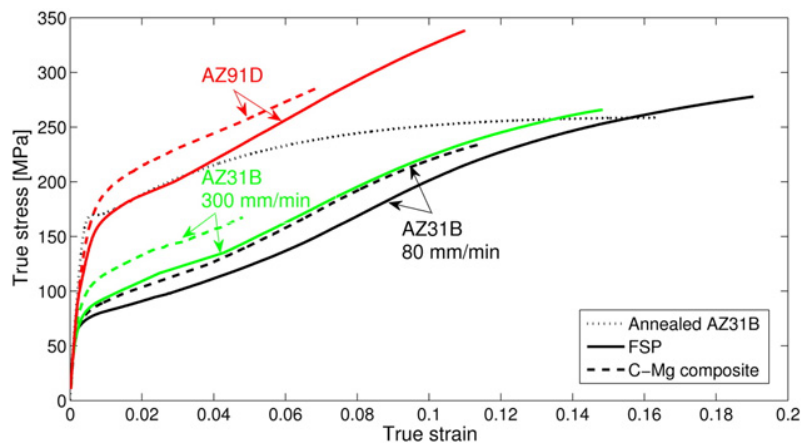

Fig. 13. True stress versus true strain tensile curves of the reference and composites samples for matrices AZ31B and AZ91D. the decrease of the ultimate tensile strength at higher advancing speed can be attributed to the occurrence of damage.

\subsubsection{Composite failure}

Although the ductility of the composites is lower than that of the FSPed reference samples, the composites still maintain good level of ductility. In particular, composite AZ31B processed at an advancing speed of $80 \mathrm{~mm} / \mathrm{min}$ exhibits a maximum elongation of 0.12 . In addition to the high Young's modulus (Section 3.2.1), such a high elongation attests that the composites are devoid of major defects. The true strain at fracture of composite AZ31B processed at $300 \mathrm{~mm} / \mathrm{min}$ is less than half the true strain at fracture of composite AZ31B processed at $80 \mathrm{~mm} / \mathrm{min}$ (Table 5 and Fig. 13). This is associated to the fact that the fibre volume fraction in composite AZ31B processed at a higher advancing speed is higher by a factor of 1.6 (Table 4).

Fig. 14 shows the fracture surface of a specimen of composite AZ91D after tensile testing. It shows evidence of fibre/matrix decohesion for fibres perpendicular to the loading direction. Composites AZ31B exhibit very similar fracture surfaces. This mode of fracture initiation results from the fact that, in the centre of the tensile specimens where the stress triaxiality is the highest, carbon fibres are oriented essentially perpendicularly to the loading direction. This suggests that it would be preferable to use a larger number of overlapping processing passes with a small shift between each pass in order to orient the fibres more favourably.

\section{Conclusions}

Short C fibres-Mg matrix composites have been produced by friction stir processing sandwiches made of a layer of $C$ fabric stacked between two sheets either of the more ductile alloy AZ31B, or of the stronger and less ductile alloy AZ91D. The following conclusions could be drawn.

- Fibre fragmentation and erosion are larger when the maximum temperature reached during FSP is lower or when the matrix material is stronger.

- A lower advancing speed brings about a broader nugget zone, which leads to a lower fibre volume fraction.

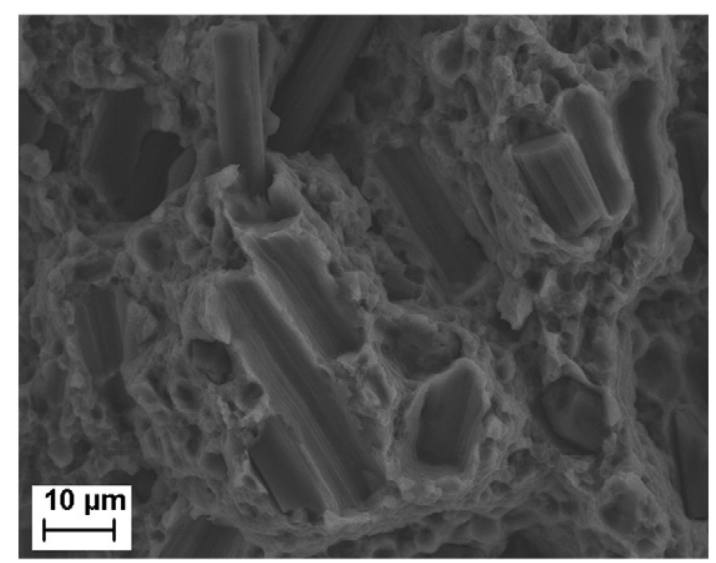

Fig. 14. Typical fracture surfaces of the composites $C$ fibres-AZ91D (similar images were found for composites AZ31B). 
- Matrix grains are smaller in the composites than in the reference FSP samples. The higher the fibre volume fraction, the lower the grain size.

- 3D X-ray tomography image analysis has revealed that, during FSP, fibres orient along the direction of the material flow. Thus, their final orientation is not reminiscent of the initial bi-modal orientation of the fibres in the fabric.

- The presence of the reinforcing phase and the grain size reduction cause an increase of the yield strength by 15 to $25 \%$ even though the fibres were not favourably oriented with respect to the loading direction.

- The fracture strain of the composites is lower than the fracture strain of the reference samples and it decreases when the fibre volume fraction increases.

Supplementary data to this article can be found online at http://dx. doi.org/10.1016/j.matchar.2015.07.010.

\section{Acknowledgements}

The authors acknowledge the financial support of the Interuniversity Attraction Poles Program from the Belgian State through the Belgian Policy Agency, contract IAP7/21 "INTEMATE". The authors also wish to thank Mr J. Halleux (Sirris Research Center, Liège) for kindly providing the AZ91D thin plates. Aurélien Pelletant is acknowledged for his help for the multi-scan tomography.

\section{References}

[1] B.L. Mordike, T. Ebert, Magnesium properties - applications - potential, Mater. Sci. Eng. A 302 (2001) 37-45.

[2] M.S. Yong, A.J. Clegg, Process optimisation for a squeeze cast magnesium alloy metal matrix composite, J. Mater. Process. Technol. 168 (2005) 262-269.

[3] H.S. Arora, H. Singh, B.K. Dhindaw, Composite fabrication using friction stir processing - a review, Int. J. Adv. Manuf. Technol. 61 (2012) 1043-1055.

[4] D. Khayyamin, A. Mostafapour, R. Keshmiri, The effect of process parameters on microstructural characteristics of $\mathrm{AZ91} / \mathrm{SiO}_{2}$ composite fabricated by FSP, Mater. Sci. Eng. A 539 (2013) 217-221.

[5] F. Delannay, L. Froyen, A. Deruyttere, The wetting of solids by molten metals and its relation in the preparation of metal-matrix composites, J. Mater. Sci. 22 (1987) 1-16.

[6] J.C. Viala, G. Claveyrolas, F. Bosselet, J. Bouix, Chemical behaviour of carbon fibres in magnesium base Mg-Al alloys, J. Mater. Sci. 35 (2000) 1813-1825.

[7] R.S. Mishra, M.W. Mahoney, S.X. McFadden, N.A. Mara, A.K. Mukherjee, High strain rate superplasticity in a friction stir processed $7075 \mathrm{Al}$ alloy, Scr. Mater. 42 (2000) 163-168.

[8] R.S. Mishra, Z.Y. Ma, Friction stir welding and processing, Mater. Sci. Eng. R 50 (2005) 1-78.

[9] Z.Y. Ma, Friction stir processing technology: a review, Metall. Mater. Trans. A 39 (2008) 642-658.

[10] M.-N. Avettand-Fènoël, A. Simar, R. Shabadi, R. Taillard, B. de Meester, Characterization of oxide dispersion strengthened copper based materials developed by friction stir processing, Mater. Des. 60 (2014) 343-357.

[11] B. Zahmatkesh, M.H. Enayati, A novel approach for development of surface nanocomposite by friction stir processing, Mater. Sci. Eng. A 527 (2010) 6734-6740.

[12] V.C. Gudla, F. Jensen, A. Simar, R. Shabadi, R. Ambat, Friction stir processing Al-TiO surface composites: anodising behaviour and optical appearance, Appl. Surf. Sci. 324 (2015) 554-562.

[13] M. Yang, C. Xu, C. Wu, K. Lin, Y.J. Chao, L. An, Fabrication of AA6061/Al2O3 nano ceramic particle reinforced composite coating by using friction stir processing J. Mater. Sci. 45 (2010) 4431-4438.

[14] R.M. Miranda, T.G. Santos, J. Gandra, N. Lopes, R.J.C. Silva, Reinforcement strategies for producing functionally graded materials by friction stir processing in aluminium alloys, J. Mater. Process. Technol. 213 (2013) 1609-1615.
[15] Y. Huang, T. Wang, W. Guo, L. Wan, S. Lv, Microstructure and surface mechanical property of AZ31 Mg/SiCp surface composite fabricated by direct friction stir processing, Mater. Des. 59 (2014) 274-278.

[16] A. Mertens, A. Simar, F. Delannay, C fibres-Mg matrix composites produced by squeeze casting and friction stir processing: microstructures \& mechanical behaviour, Mater. Sci. Forum 706-709 (2012) 1221-1226.

[17] A. Mertens, A. Simar, H.-M. Montrieux, J. Halleux, F. Delannay, J. Lecomte-Beckers, Friction stir processing of magnesium matrix composites reinforced with carbon fibres: influence of the matrix characteristics and of the processing parameters on the microstructural developments, in: W.J. Poole, K.U. Kainer (Eds.),Proc. of the 9th Int. Conf. on Magnesium Alloys and Their Applications 2012, pp. 845-850.

[18] W. Yuan, S.K. Panigrahi, R.S. Mishra, Achieving high strength and high ductility in friction stir-processed cast magnesium alloy, Metall. Mater. Trans. A 44 (2013) 3675-3684.

[19] I.J. Polmear, Light Alloys: From Traditional Alloys to Nanocrystals, 4th ed. Elsevier/ Butterworth-Heinemann, Oxford, Burlington, MA, 2006. 239.

[20] C. Salmon, F. Boland, C. Colin, C. Leroy, F. Delannay, Properties of lead anodes reinforced by carbon or glass creep fibers, Intérêts technologiques et marchés potentiels des composites à matrice métallique - Actes du colloque franco-canadien de septembre 1995. Les Presses de l'Ecole des Mines, Paris, 1997. 170-189.

[21] C. Jonckheere, B. de Meester, A. Denquin, A. Simar, Torque, temperature and hardening precipitation evolution in dissimilar friction stir welds between 6061-T6 and 2014-T6 aluminum alloys, J. Mater. Process. Technol. 213 (2013) 826-837.

[22] Y.H. Yin, N. Sun, T.H. North, S.S. Hu, Hook formation and mechanical properties in AZ31 friction stir spot welds, J. Mater. Process. Technol. 210 (2012) 2062-2070.

[23] J.-Y. Buffiere, E. Maire, J. Adrien, J.-P. Masse, E. Boller, In situ experiments with X ray tomography: an attractive tool for experimental mechanics, Exp. Mech. 50 (2010) 289-305.

[24] C. Landron, E. Maire, O. Bouaziz, J. Adrien, L. Lecarme, A. Bareggi, Validation of void growth model using X ray microtomography characterization of damage in dual phase steels, Acta Mater. 59 (2011) 7564-7673.

[25] W.B. Lee, Y.M. Yeon, S.B. Jung, Joint properties of friction stir welded AZ31B-H24 magnesium alloy, Mater. Sci. Technol. 19 (2003) 785-790.

[26] A. Razal Rose, K. Manisekar, V. Balasubramanian, Influences of welding speed on tensile properties of friction stir welded AZ61A magnesium alloy, J. Mater. Eng. Perform. 21 (2012) 257-265.

[27] F.J. Humphrey, M. Hatherly, Recrystallization and Related Annealing Phenomena, 2nd ed. Elsevier, Oxford, 2004. 285-319.

[28] A. Wójcicka, K. Mroczka, P. Kurtyka, M. Binkowski, Z. Wróbel, X ray microtomography analysis of the aluminum alloy composite reinforced by $\mathrm{SiC}$ after friction stir processing, J. Mater. Eng. Perform. 23 (2014) 3215-3221.

[29] M. Knezevic, A. Levinson, R. Harris, R.K. Mishra, R.D. Doherty, S.R. Kalidindi, Deformation twinning in AZ31: influence on strain hardening and texture evolution, Acta Mater. 58 (2010) 6230-6242.

[30] L. Cizek, M. Greger, L. Pawlica, L.A. Dobrzanski, T. Tanski, Study of selected properties of magnesium alloy AZ91 after heat treatment and forming, J. Mater. Process. Technol. 157-158 (2004) 466-471.

[31] T.W. Clyne, P.J. Withers, An Introduction to Metal Matrix Composites, Cambridge University Press, Cambridge, UK, 1993. 20-30.

[32] S.R. Agnew, J.A. Horton, T.M. Lillo, D.W. Brown, Enhanced ductility in strongly textured magnesium produced by equal channel angular processing, Scr. Mater. 50 (2004) 377-381.

[33] W. Yuan, R.S. Mishra, Grain size and texture effects on deformation behavior of AZ31 magnesium alloy, Mater. Sci. Eng. A 558 (2012) 716-724.

[34] R. Xin, B. Li, A. Liao, Z. Zhou, Q. Liu, Correlation between texture variation and transverse tensile behavior of friction-stir-processed AZ31 Mg alloy, Metall. Mater. Trans. A 43 (2012) 2500-2508.

[35] J. Yang, B.L. Xiao, D. Wang, Z.Y. Ma, Effects of heat input on tensile properties and fracture behavior of friction stir welded Mg-3Al-1Zn alloy, Mater. Sci. Eng. A 527 (2010) 708-714.

[36] R. Xin, D. Liu, B. Li, L. Sun, Z. Zhou, Q. Liu, Mechanisms of fracture and inhomogeneous deformation on transverse tensile test of friction-stir-processed AZ31 Mg alloy, Mater. Sci. Eng. A 565 (2013) 333-341.

[37] J.A. del Valle, P. Rey, D. Gesto, D. Verdera, J.A. Jimenez, O.A. Ruano, Mechanical properties of ultra-fine grained AZ91 magnesium alloy processed by friction stir processing, Mater. Sci. Eng. A 628 (2015) 198-206.

[38] S.H. Park, S.G. Hong, C.S. Lee, Activation mode dependent $\{10-12\}$ twinning characteristics in a polycristalline magnesium alloy, Scr. Mater. 62 (2010) 202-205.

[39] S. Kalpakjian, S.R. Schmid, Manufacturing Engineering and Technology, 6th ed. Pearson, Singapore, 2010. 72. 